\title{
THE BRITISH RADIOLOGICAL PROTECTION ASSOCIATION AND THE JOINT HEALTH PHYSICS COMMITTEE
}

\begin{abstract}
GCIENCISTS of many specialities are concerned with N some aspects of what, for want of a better name, has usually been referred to as 'health physics'. This may be taken to be the investigation of problems of radiological protection including, for example, radiation dosimetry and operational techniques connected with the use of ionizing radiations in industry, medicine and scientific research. Some co-operation of the various appropriate learned societies and other bodies concerned was therefore felt to be desirable, and in December 1961 the Joint Health Physics Committee was set up to co-ordinate the arrangement of symposia in this field. This Committee had representation from the British Institute of Radiology, the British Occupational Hygiene Society, the Faculty of Radiologists, the Hospital Physicists' Association, the Institute of Physics and the Physical Society, the Radiological Protection Service, and the Health and Safety Branches of the Central Electricity Generating Board and the United Kingdom Atomic Energy Authority. After its formation in 1963, the Society for Radiological Protection was also represented.
\end{abstract}

This co-operation was fruitful, each organization in turn arranging a symposium open also to interested members of the other organizations. Some twelve sym. posia have been held during the period 1962-65 with attendance between 150 and 300 , the distribution between the various specialities varying with the nature of the subject.

The Health Physics Society, which was formed in the United States in 1955, was intended to be an international organization. In fact, by 1964 it did have some 20 per cent of its membership in some fifty countries outside the United States, and a number of national sections (including the Society for Radiological Protection in the United Kingdom) had been formed. However, it was apparent that other national or regional health physics organizations were also being formed and, with the initiative of Dr. K. Z. Morgan, of the Health Physies Society, discussions were started with representatives of many countries for the formation of an International Radiation Protection Association to promote international scientific co-operation in health physics and, at intervals, to arrange international meetings in this field. A provisional constitution was agreed at a meeting in Paris in December 1964, under which the International Radiation Protection Association was to consist of an affiliation of national societies (ono from each country or region) with individual members of these societies having, as appropriate to their qualifications, either full or associate membership of the Association.

To meet this new situation, and after detailed discussions between the societies concerned with the Joint Health Physics Committee, it was agreed to form instead the British Radiological Protection Association. This is an affiliation of learned societies concerned with radiological protection, formed to affiliate itself to the International Radiation Protection Association as the associate society for the United Kingdom. For a small annual subscription (at present $10 s$. per annum) interested members of any of the constituent societies may then join the British and also automatically the International Radiation Protection Association as individual full or associate members, according to their qualifications as laid down in the constitution of the International Radiation Protection Association. The Joint Committee of the British Radiological Protection Association has ropresentation from each of the constituent societies (together with one or two non-voting co-opted members) and will function in plaee of the Joint Health Physics Committee to co-ordinate the arrangement of symposia on health physics subjects in Britain. It will also arrange for dis. cussion of relevant topics with the British representatives of the British Radiological Protection Association on the executive council of the International Association, who, under the constitution, will have been elected by a ballot of the individual full members of the Association.

The founder constituent societies of the British Radiological Protection Association are the British Institute of Radiology, the British Occupational Hygiene Society, the Faculty of Radiologists, the Hospital Physicists' Association and the Society for Radiological Protection (now no longer a section of the Health Physics Society). The Society of Radiographers has also been accepted as a constituent society. That there is general support for the Association is ovident from the fact that already more than three hundred individual full members have been registered and accepted for membership of the British and International Associations. This number will entitle the British Radiological Protection Association to five votes on the executive council of the international body.

Affiliations to the International Radiation Protection Association have now been accepted from a total of eleven societies, including organizations in France, the United States, Luxembourg, Scandinavia, Japan, United Kingdom, Belgium, Israel, Italy, Netherlands and Central Europe, and other applications are pending. Thus, the International Association is well established and its first International Congress is to be held in Rome in September 1966.

Meanwhile, the Joint Committee of the British Radiological Protection Association is planning two symposia in the United Kingdom in November 1966, one to be organized by the Faculty of Radiologists on "Radiation Genetics", and the other to be organized by the British Occupational Hygiene Society on the "Hazards Associated with the Use of Lasers". It is to be hoped, therefore, that such co-operation, both nationally and internationally, will be of general and scientific value to those concerned with the various aspects of radiological protection.

Further details of the British Radiological Protection Association and its functions can be obtained from any of the constituent socicties, or from the honorary secretary of the Joint Committee, Mr. R. Oliver, the University Radiation Protection Office, 15 Parks Road, Oxford.

R. OLIVER

\section{NUCLEAR AND ENGINEERING CERAMICS}

$\mathrm{T}$ HE position of ceramics in nuclear engineering is now well established. The same cannot be said for their structural applications in engineering if the relative number of papers on these two aspects presented at the meeting of the Basic Science Section of the British Ceramic Society held at the Atomic Energy Research Establish- ment, Harwell, during October 25-27, 1965, is truly representative. Of the thirty papers presented, only five dealt with potential non-nuclear applications. $\mathrm{Mr}$. N. Parr (Admiralty Materials Laboratory, Poole, Dorset) discussed the difficulties encountered in attempts to establish the technology of reaction-bonded silicon nitride and its 